\title{
Drag Reduction Properties of Nanofluids in Microchannels
}

\author{
H.A. Abdulbari* and F.L.W. Ming \\ Centre of Excellence for Advanced Research in Fluid Flow; Faculty of Chemical Engineering and Natural Resources, Universiti \\ Malaysia Pahang, Gambang 26300, Kuantan, Pahang, Malaysia.
}

Received 21 November 2014; Accepted 1 July 2015

\begin{abstract}
An experimental investigation of the drag reduction (DR) individualities in different sized micro channels was carried out with nanopowder additives (NAs) (bismuth(III) oxide, iron(II/III) oxide, silica, and titanium(IV) oxide) water suspensions/fluids. The primary objective was to evaluate the effects of various concentrations of NAs with different microchannel sizes $(50,100$, and $200 \mu \mathrm{m})$ on the pressure drop of a system in a single phase. A critical concentration was observed with all the NAs, above which increasing the concentration was not effective. Based on the experimental results, the optimum DR percentages were calculated. The optimum percentages were found to be as follows: bismuth III oxides: $\sim 65 \%$ DR, 200 ppm and a microchannel size of $100 \mu \mathrm{m}$; iron II/III oxides: $\sim 57 \%$ DR, $300 \mathrm{ppm}$, and a microchannel size of $50 \mu \mathrm{m}$; titanium IV oxides: 57\% DR, 200 ppm, and a microchannel size of $50 \mu \mathrm{m}$, and silica: 55\% DR, $200 \mathrm{ppm}$, and a microchannel size of $50 \mu \mathrm{m}$.
\end{abstract}

Keywords: Microchannels, Pressure drop, Drag reduction, Nanopowder additives.

$$
\text { خواص المقاومة الهيدروليكية للموائع النانوية ِِ القنوات الميكروية الصفيرة }
$$

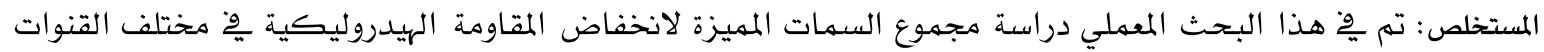

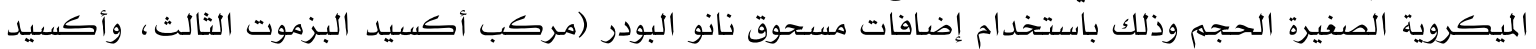

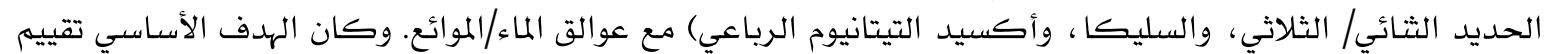

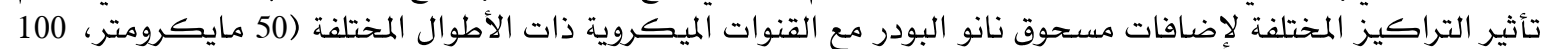

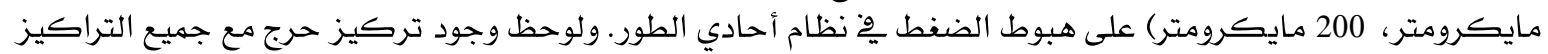

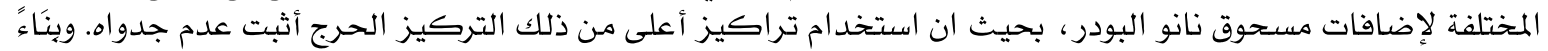

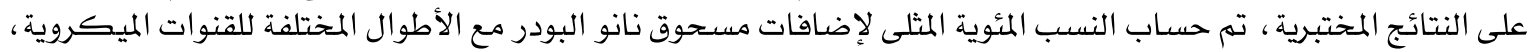

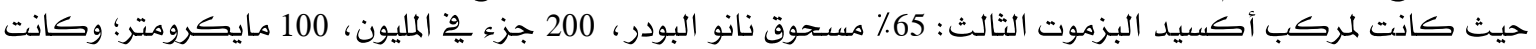

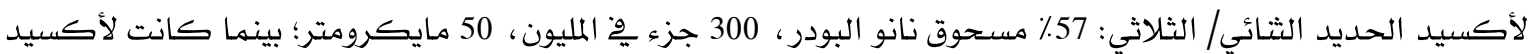

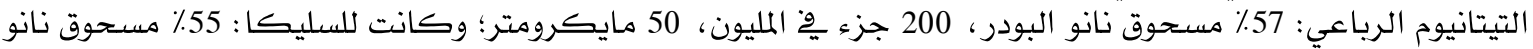

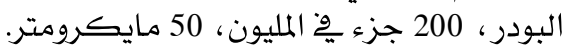

الكلمات المفتاحية : القنوات الميكروية الصغيرة، هبوط الضغط، المقاومة الهيدروليكية ، إضافات مسحوق نانو البودر

*Corresponding authors' e-mail: hayder.bari@gmail.com 


\section{Introduction}

The study of drag reduction (DR) in microchannels has raised considerable interest in researchers all over the world. DR additives (DRAs), such as polymers, surfactants, and microbubbles, have proven their effectiveness and are appreciated by many industries for their economic value (Nghe et al. 2010).

The use of diverse polymers such as DRAs has been reported previously (Abubakar et al. 2014; AlSarkhi 2012; Matras and Kopiczak 2015; Edomwonyi-Outu, Chinaud and Angeli 2015; Hong et al. 2015; Iaccarino et al. 2010; Resende et al. 2011) and surfactants (Drzazga et al. 2013; Li et al. 2008; Różański 2011; Yu and Kawaguchi 2006; Tuan Mizunuma 2013; Qi et al. 2011) depending upon the polarities and different behaviors in a turbulent flow (Tarn and Pamme 2014), while the impact of other colloidal suspensions, such as nanofluids, in reducing the pressure drop has not been widely studied. The dispersion quality of the nanoparticles in the base fluid and the stability of the suspension play a crucial role in most applications of practical interest (Rivet et al. 2011; Xie et al. 2003; Choi et al. 2007; Ganguly et al. 2009). Zhao et al. (2009) studied the viscosity of silicon dioxide nanofluids with different particle sizes and $\mathrm{pH}$ values. The results revealed that the nanoparticle diameter is of crucial importance to the viscosity of a nanofluid. The smaller the nanoparticles, the larger the viscosity and the greater the dependence on the nanofluid volume fraction. Zhao et al. (2009) studied the effect of silica-based nanofluids as DRAs. The results suggested that the DR enhanced increasing nanofluid concentrations up to a critical concentration, above which no significant DR was observed. Pouranfard. (2014) observed an increase in the viscosity of a fluid with increasing concentrations of nanofluid DRAs and decreases in temperature. Kostic (2013) reported a comparative study of silica and carbon nanotubes (CNTs), where the CNTs were found to be better DRAs $(75 \%)$ than silica with a maximum reduction of $60 \%$ (Yang et al. 2005).

Very few studies have been done on DR using nanoparticles compared to polymers and surfactants. Therefore, in this study, nanofluids at different operating conditions were injected through microchannels, and the effects of different parameters on DR were investigated. Pressure drop was calculated as a function of flow rate (rpm) in different sized microchannels (50, 100, and $200 \mu \mathrm{m})$ by varying the concentration of different types of oxide nanoparticles, including bismuth, iron, silica, and titanium. The pressure drop was later applied in calculating the DR efficacy (\%DR) of a particular nanofluid. In addition, the effect of flow rate and channel size on DR was also investigated.

\section{Experimental Procedure}

\subsection{Materials}

Bismuth(III) oxide, iron(II, III) oxide, titanium (IV) oxide, and silicon(II) oxide were purchased from Sigma-Aldrich (St. Louis. Missouri, USA) and used without any alterations [Table 1]. Deionized water was used to prepare samples and make dilutions.

Table 1. Physical properties of nanoparticles used.

\begin{tabular}{lccc}
\hline $\begin{array}{l}\text { Working } \\
\text { fluids }\end{array}$ & $\begin{array}{c}\text { M. } \\
\text { weight } \\
(\mathrm{g} / \mathbf{m o l})\end{array}$ & Size & $\begin{array}{l}\text { Density } \\
(\mathrm{g} / \mathrm{mL})\end{array}$ \\
\hline $\begin{array}{l}\text { Bismuth(III) } \\
\text { oxide } \\
\left(\mathrm{Bi}_{2} \mathrm{O}_{3}\right)\end{array}$ & 465.96 & $90-$ & $0.5-1.1$ \\
$\begin{array}{l}\mathrm{Iron}(\mathrm{II}, \mathrm{III}) \\
\text { oxide }\end{array}$ & 251.53 & $50-$ & $4.8-5.1$ \\
$\left(\mathrm{Fe}_{3} \mathrm{O}_{4}\right)$ & & 100 & \\
$\mathrm{Silica}_{\left(\mathrm{SiO}_{2}\right)}$ & 60.08 & $200-$ & 0.037 \\
$\begin{array}{l}\mathrm{Titanium}(\mathrm{IV}) \\
\text { oxide }\end{array}$ & 79.87 & $<100$ & - \\
$\left(\mathrm{TiO}_{2}\right)$ & & & \\
\hline
\end{tabular}

\subsection{Nanofluid Solution Preparation}

Nanoparticle solutions were prepared in deionized water for each oxide at five different concentrations, ranging from 100-500 ppm. The fluids were homogenized at high speed for 10 minutes with a stirrer and then left overnight on low speed to achieve maximum dispersion. Before running each experiment, the solution was stirred for two hours at $100 \mathrm{rpm}$ to avoid any agglomeration.

\subsection{Experimental Setup}

Straight microchannels of 50, 100, and $200 \mu \mathrm{m}$ with a length of $58.5 \mathrm{~mm}$ (TOPAS Advanced Polymers, Frankfurt-Höchst, Germany) were employed in this study. The solution was transferred through two syringes via a syringe pump (model SN-50F6) connected to a T-junction connection whose outlet was connected to another T-junction connection. A pressure transmitter (model: STK336) and the inlet of the microchannel were connected to the outlet of the second $\mathrm{T}$ - 
junction connection. The solutions were pumped into the microchannel via connecting tubes.

The flow rate of the solutions was controlled using the syringe pump. The flow of the liquid in the microchannel was observed using an HBO 50 microscope (Zeiss International, Oberkochen, Germany) connected to a camera. The pressure drop across the microchannel was observed using the pressure transmitter and the results were recorded. The \%DR was calculated using Eqn. 1.

$$
\% \mathrm{DR}=\frac{\Delta \mathrm{P}_{\mathrm{b}}-\Delta \mathrm{P}_{\mathrm{a}}}{\Delta \mathrm{P}_{\mathrm{b}}} \times 100
$$

Where,

$$
\begin{aligned}
& \Delta \mathrm{P}_{\mathrm{b}}=\text { pressure drop before adding DRA } \\
& \Delta \mathrm{P}_{\mathrm{a}}=\text { pressure drop after adding DRA }
\end{aligned}
$$

\section{Results and Discussion}

A series of experiments were performed to study the effects of nanofluid concentration, microchannel size, and flow rate on pressure drop and \%DR. It was found that the \%DR rises with increasing nanofluid concentration. However, there is a critical concentration above which no more reduction can be attained. In the present study, the critical concentration obtained was almost the same for all oxide nanoparticles (200 ppm) with the exception of $\mathrm{Fe}_{3} \mathrm{O}_{4}(300 \mathrm{ppm})$ [Table 2].

Figure 1 presents a comparison of the pressure drop at the critical concentrations of nanofluids and deionized water versus the flow rate in the microchannels. A regular pressure drop trend was observed with an increasing flow rate in all cases. Increasing the flow rate increases the degree of turbulence which provides a better platform for DRAs to perform (Stone and Ajdari 2014). $\mathrm{SiO}_{2}$ showed a maximum pressure drop at its critical concentration, which may be due to the fact that the mechanism of $\mathrm{DR}$ by $\mathrm{SiO}_{2}$ nanoparticles is mainly a surface modification. The $\mathrm{SiO}_{2}$ nanoparticles have good rigidity and reduce the friction factor through dispersion into the liquid phase and contact with the pipe surface, so a higher pressure drop was observed (Zhao et al. 2009).

Figures 2-5 show the \%DR versus the rate of flow in the different sized microchannels and at different oxide nanoparticle concentrations. The $\mathrm{DR}$ is greater with smaller particles as the smaller sized particles with larger surface areas result in the migration effect, where a bond is formed between the transporting fluid molecules and the DR agents (Khadom and Abdul-Hadi 2014). It was observed that the use of nanofluids at low concentrations did not cause a serious reduction in the pressure drop which is due to the small size of the nanoparticles (Abdulbari, Shabirin and Abdurrahman 2013).

The diameter of the microchannels does not seem to affect the \% DR greatly in contrast to the behavior usually observed with a reduction in diameter (Lee and Mudawar 2007). The effect of solution velocity $(\mathrm{m})$ on the $\% \mathrm{DR}$ was studied in terms of the volumetric flow rate. The results show that the \%DR increases with increasing fluid velocity. Increasing the fluid velocity means increasing the degree of turbulence inside the pipe, which will provide a better medium for the drag reducer to be more effective (Byrne, Hart and da Silva 2012).

Figure 2 presents the \% DR while keeping the concentration constant for all the nanofluids at 100 ppm with varying microchannel sizes $(50,100$, and $200 \mu \mathrm{m})$. An increase in \% DR was observed when increasing the microchannels' sizes from 50 to 200 $\mu \mathrm{m}$. This can be explained by the presence of large

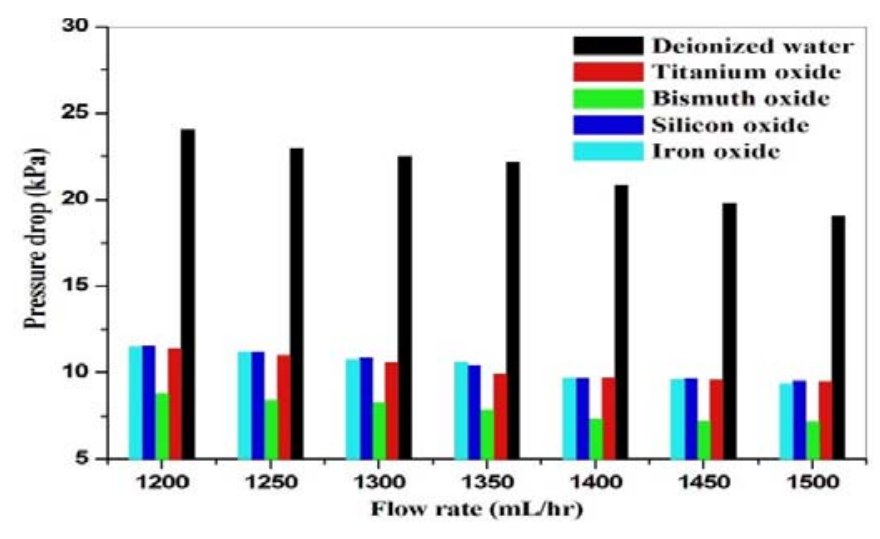

Figure 1. A comparative study of pressure drop between deionized water and oxides used in the study. 
Table 2. Parameters affecting the drag reduction in different nanofluids.

\begin{tabular}{|c|c|c|c|c|c|}
\hline \multirow[t]{2}{*}{ Oxide } & Channel size & Critical Con. & Flow rate & $\begin{array}{c}\text { Pressure } \\
\text { drop }\end{array}$ & Drag reduction \\
\hline & $\mu \mathrm{m}$ & ppm & $\mathrm{ml} / \mathrm{hr}$ & $\mathrm{kPa}$ & $\%$ \\
\hline \multirow{3}{*}{ Titanium } & 50 & 200 & 1350 & 9.93 & 56.9 \\
\hline & 100 & 200 & 1250 & 10.74 & 53.3 \\
\hline & 200 & 200 & 1350 & 9.34 & 51.3 \\
\hline \multirow{3}{*}{ Bismuth } & 50 & 200 & 1400 & 8.28 & 63.0 \\
\hline & 100 & 200 & 1400 & 7.35 & 64.8 \\
\hline & 200 & 200 & 1200 & 8.67 & 57.5 \\
\hline \multirow{3}{*}{ Silicon } & 50 & 200 & 1350 & 10.35 & 55.1 \\
\hline & 100 & 200 & 1400 & 9.99 & 52.1 \\
\hline & 200 & 200 & 1400 & 9.68 & 57.6 \\
\hline \multirow{3}{*}{ Iron } & 50 & 300 & 1450 & 9.59 & 56.8 \\
\hline & 100 & 300 & 1350 & 9.66 & 56.5 \\
\hline & 200 & 300 & 1350 & 9.94 & 48.2 \\
\hline
\end{tabular}
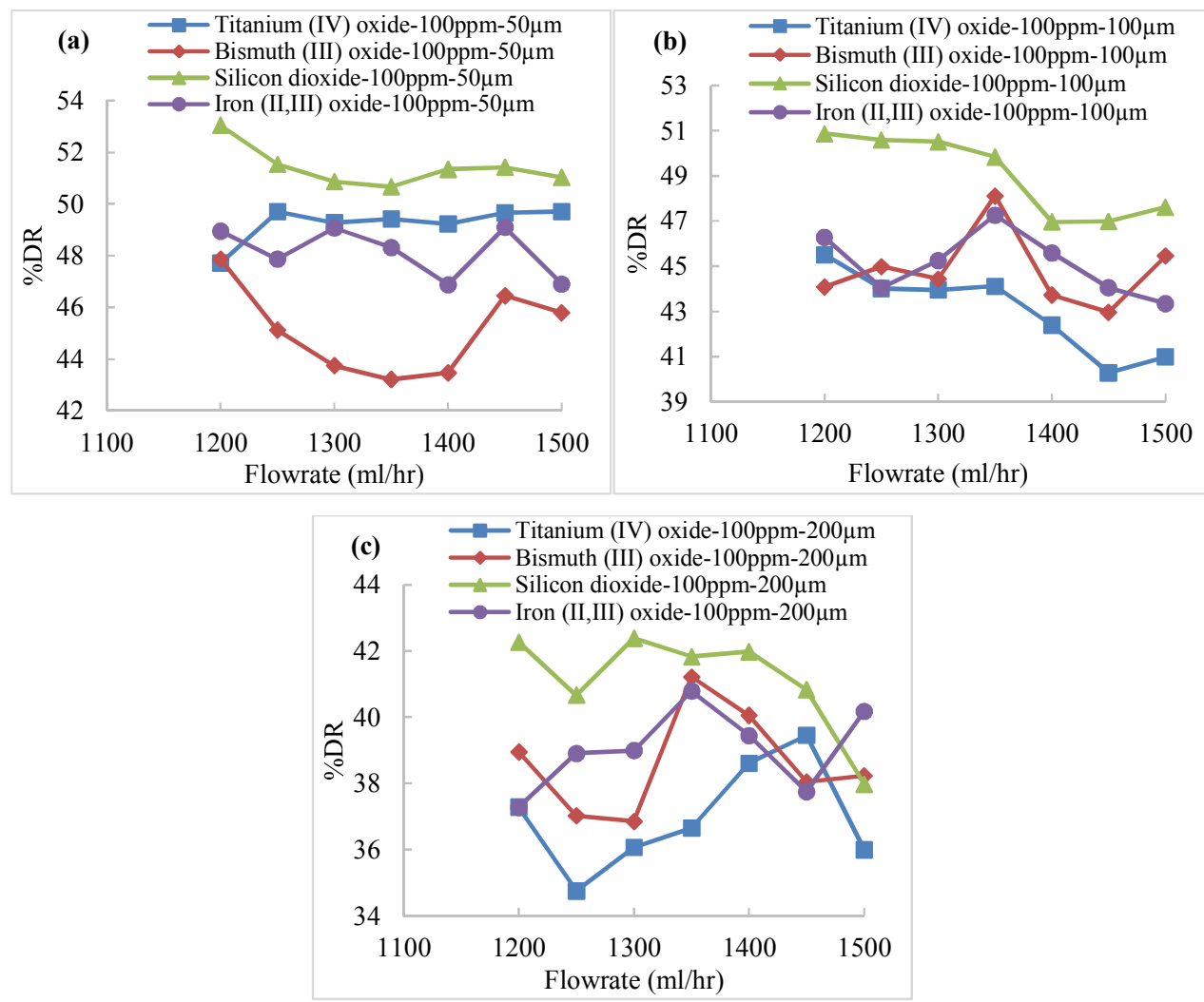

Figure 2. Variations of \%DR with a nanofluid concentration of $100 \mathrm{ppm}$. 

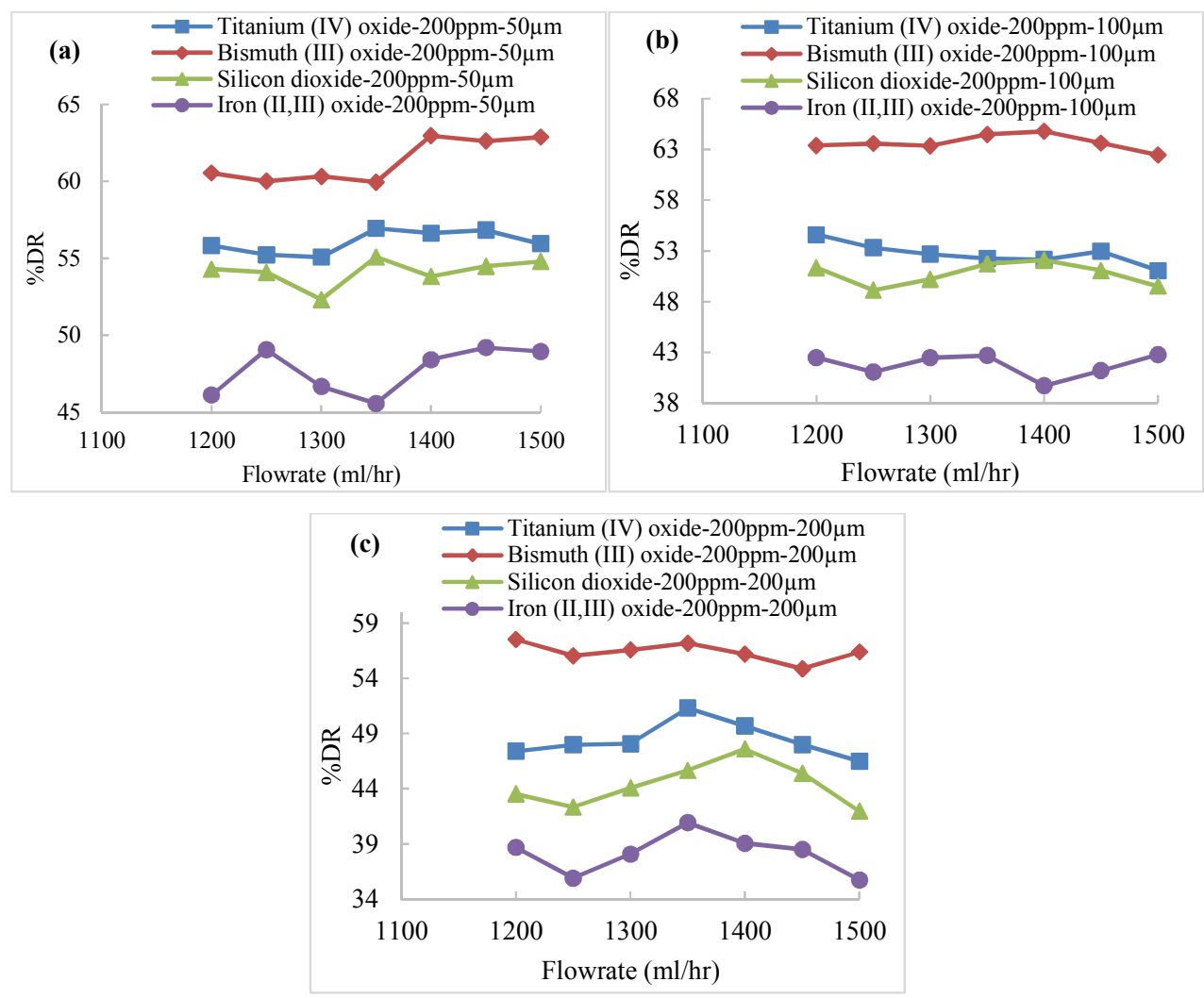

Figure 3. Variations of \%DR with nanofluid concentration of $200 \mathrm{ppm}$.
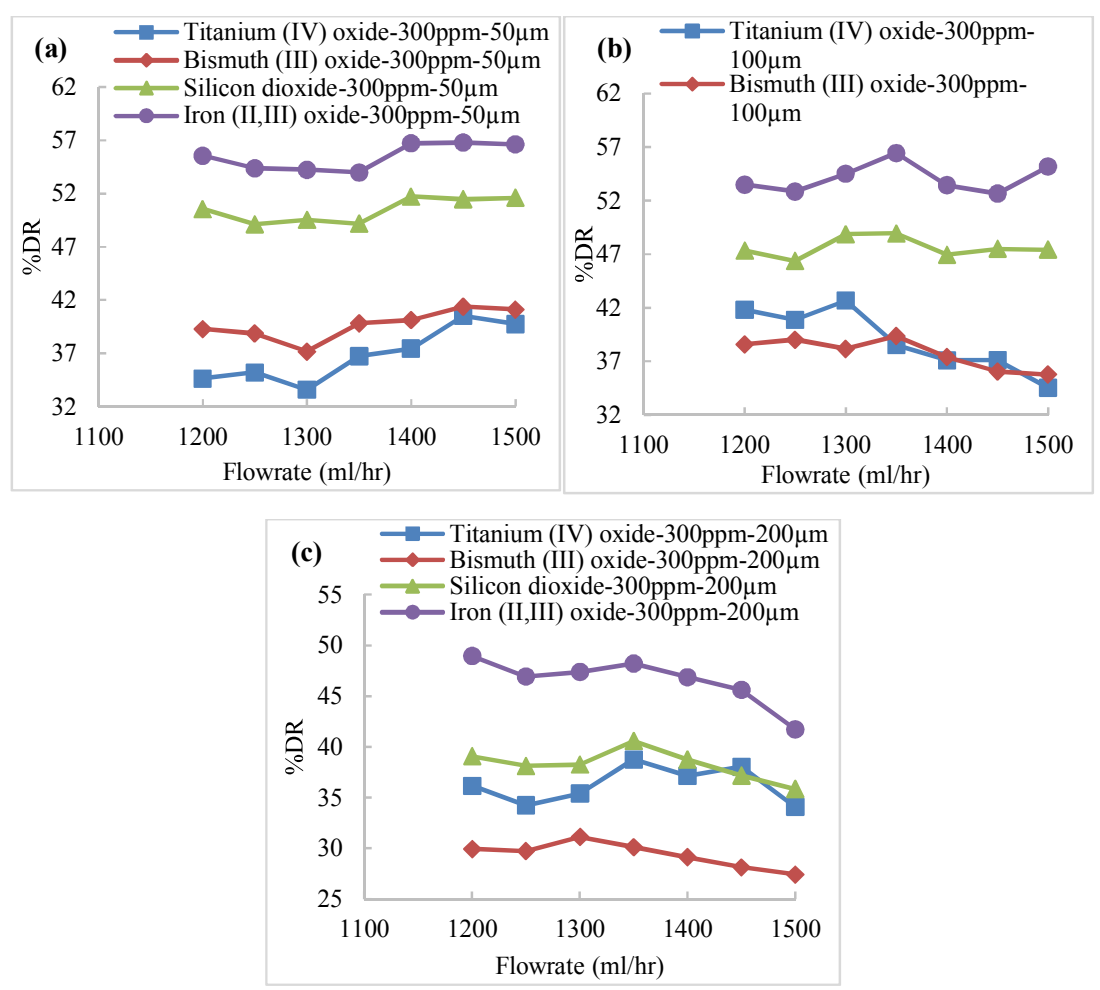

Figure 4. Variation in \%DR at a nanofluid concentration of $300 \mathrm{ppm}$. 


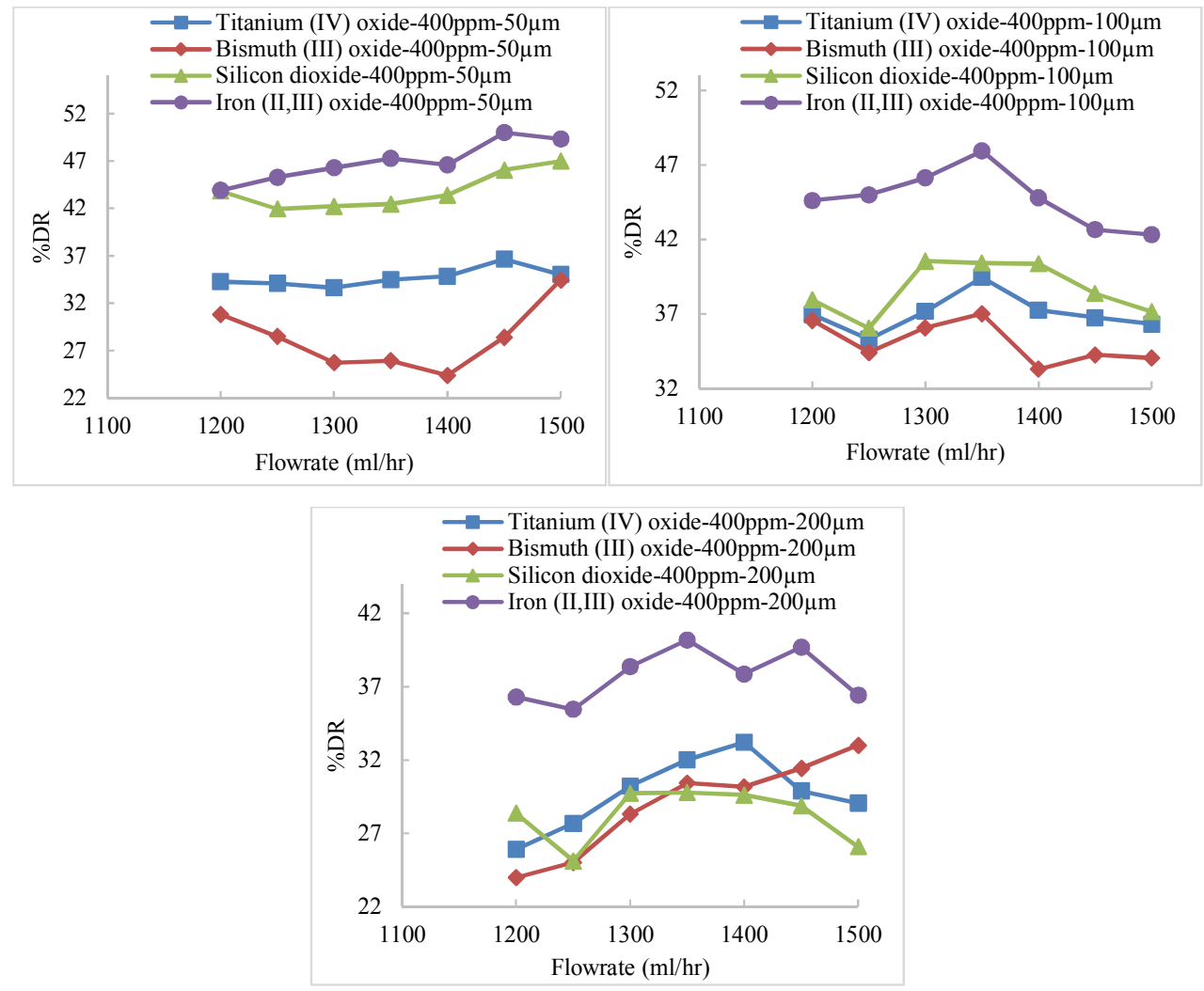

Figure 5. Variations in $\% \mathrm{DR}$ at nanofluid concentrations of $400 \mathrm{ppm}$.

eddies in the larger microchannels which absorb a large amount of energy from the flow. In smaller microchannels, more smaller eddies are formed, but some small eddies are unable to absorb enough energy and are incapable of overcoming the viscosity resistance (Kim et al. 2000; Khadom and Abdul-Hadi 2014; Al-Sarkhi and Hanratty 2001). $\mathrm{SiO}_{2}$ exhibited the highest \%DR of all the microchannels, which may be due to the larger sized silica particles settling down quickly and further decreasing the diameter of the microchannels.

Figure 3 depicts the maximum DR achieved in all the oxides except for $\mathrm{Fe}_{3} \mathrm{O}_{4}$ nanofluids at a concentration of $200 \mathrm{ppm}$, which is a clear indication of reaching a critical concentration. $\mathrm{Bi}_{2} \mathrm{O}_{3}$ exhibited the highest \% DR $(\sim 65 \%)$ at the critical concentration with a microchannel size of $100 \mu \mathrm{m}$ at $1400 \mathrm{rpm}$ which reduced to $200 \mu \mathrm{m}$-sized microchannels $(\sim 58 \%)$ with a flow rate of $1200 \mathrm{rpm}$. In the case of $\mathrm{SiO}_{2}$ and $\mathrm{TiO}_{2}$, the maximum drag achieved at the critical concentration was $\sim 57.5$ and $\sim 57 \%$ with 200 and $50 \mu \mathrm{m}$-sized microchannels, respectively.

The iron oxide nanofluid exhibited maximum DR at a concentration of $300 \mathrm{ppm}$ in all the microchannels [Fig. 4]. Maximum DR ( $56.8 \%)$ was achieved with $50 \mu \mathrm{m}$-sized microchannels and a flow rate of $1400 \mathrm{~mL} / \mathrm{hr}$. In cases of $100 \mu \mathrm{m}$-sized microchannels, a nearly identical increasing trend was observed and maximum drag reduction $(\sim 56.5 \%)$ was observed at a slightly lower flow rate (1350 mL/hr). A decreasing trend in drag was observed for all the other oxides, which confirmed that all the oxides had reached their critical concentration limit; increasing the concentration further had no more effect on the pressure drop in a flow.

A gradual decrease in the DR properties of the iron oxide nanofluid was observed at $400 \mathrm{ppm}$ [Fig. 5], emphasizing that iron oxide nanofluids are more effective in the concentration range of 300-400 ppm.

All the other nanofluids exhibited a very low DR; thus, it is obvious that, after a critical limit has been reached, increasing the concentration has no positive effect on DR efficiency and a negative impact on the flow of a system.

\section{Conclusions}

To conclude, the DR performances of different nanofluids were studied at diverse concentrations in 
different sized microchannels. It was observed that all the nanofluids exhibited a certain critical concentration above which increasing the concentration had no greater impact on the pressure drop or the DR of the system. Increasing the flow rate also had an impact on DR efficiency, but it was noticed that, above the critical concentration limit, the flow rate did not have much effect on the \%DR. The channel size was found to have no effect on the DR efficiency of the nanofluids.

\section{Acknowledgments}

Authors are grateful to Universiti Malaysia Pahang, for financial assistance.

\section{References}

Abubakar A, Al-Wahaibi T, Al-Wahaibi Y, AlHashmi AR, Al-Ajmi A (2014), Roles of drag reducing polymers in single- and multi-phase flows. Chemical Engineering Research and Design 92(11): 2153-2181.

Al-Sarkhi A (2012), Effect of mixing on frictional loss reduction by drag reducing polymer in annular horizontal two-phase flows. International Journal of Multiphase Flow 39: 186-192.

Al-Sarkhi A, Hanratty TJ (2001), Effect of pipe diameter on the performance of drag-reducing polymers in annular gas-liquid flows. Chemical Engineering Research and Design 79(4): 402-408.

Byrne M, Hart R, da Silva A (2012), Experimental thermal hydraulic evaluation of $\mathrm{CuO}$ nanofluids in microchannels at various concentrations with and without suspension enhancers. International Journal Heat Mass Transfer 55: 2684-2691.

Choi CS, Park SJ, Choi HJ (2007), Carbon nanotube/polyaniline nanocomposites and their electrorhelogical characteristics under an applied electric field. Current Applications in Physics 7: 352355.

Drzazga M, Gierczycki A, Dzido G, Lemanowicz M (2013), Influence of nonionic surfactant addition on drag reduction of water based nanofluid in a small diameter pipe. Chinese Journal of Chemical Engineering 21(1): 104-108.

Edomwonyi-Otu LC, Chinaud M, Angeli P (2015), Effect of drag reducing polymer on horizontal liquid-liquid flows. Experimental Thermal and Fluid Science 64: 164-174.

Ganguly S, Sikdar S, Basu S (2009), Experimental investigation of the effective electrical conductivity of aluminum oxide nanofluids. Powder Technology 196: 326-330.
Hong C, Choi HJ, Zhang K, Renou F, Grisel M (2015), Effect of salt on turbulent drag reduction of xanthan gum. Carbohydrate Polymers 121: 342-347.

Iaccarino G, Shaqfeh ESG, Dubief Y (2010), Reynolds-averaged modeling of polymer drag reduction in turbulent flows. Journal of NonNewtonian Fluid Mechanics 165(7-8): 376-384.

Khadom AA, Abdul-Hadi AA (2014), Performance of polyacrylamide as drag reduction polymer of crude petroleum flow. Ain Shams Engineering Journal 5(3): 861-865.

Kim NJ, Lee JY, Yoon SM, Kim CB, Hur BK (2000), Drag reduction rates and degradation effects on synthetic polymer solution with surfactant additives. Journal of Industrial and Engineering Chemistry 6: 412-418.

Kostic MM (2013), Friction and heat transfer characteristics of silica and CNT nanofluids in a tube flow. Proceedings of the $8^{\text {th }}$ Annual International Conference on Energy and Environment, Rhodes Island, Greece.

Lee J, Mudawar I (2007), Assessment of the effectiveness of nanofluids for single phase and two-phase heat transfer in micro-channels. International Journal of Heat Mass Transfer 50(3-4): 452-463.

Li FC, Kawaguchi Y, Yu B, Wei JJ, Hishida K (2008), Experimental study of drag-reduction mechanism for a dilute surfactant solution flow. International Journal of Heat and Mass Transfer 51(3-4): 835-843.

Matras Z, Kopiczak B (2015), Intensification of drag reduction effect by simultaneous addition of surfactant and high molecular polymer into the solvent. Chemical Engineering Research and Design 96: 35-42.

Nghe P, Tabeling P, Ajdari A (2010), Flow-induced polymer degradation probed by a high throughput microfluidic set-up. Journal of NonNewtonian Fluid Mechanics 165(7-8): 313-322.

Pouranfard AR, Mowla D, Esmaeilzadeh F (2014), An experimental study of drag reduction by nanofluids through horizontal pipe turbulent flow of a Newtonian liquid. Journal of Industrial and Engineering Chemistry 20(2): 633-637.

Qi Y, Kesselman E, Hart DJ, Talmon Y, Mateo A, Zakina JL (2011), Comparison of oleyl and elaidyl isomer surfactant-counterion systems in drag reduction, rheological properties and nanostructure. Journal of Colloid and Interface Science 354(2): 691-699.

Resende PR, Kim K, Younis BA, Sureshkumar R, Pinhoa RT (2011), A FENE-P k- $\varepsilon$ turbulence model for low and intermediate regimes of polymerinduced drag reduction. Journal of Non-Newtonian Fluid Mechanics 166(12-13): 639-660. 
Rivet C, Hirsch A, Hamilton S, Lu H (2011), Microfluidics for Medical Diagnostics and Biosensors. Chemical Engineering Science 66: 14901507.

Różański J (2011), Flow of drag-reducing surfactant solutions in rough pipes. Journal of Non-Newtonian Fluid Mechanics 166(5-6): 279-288.

Stone HA, Ajdari A (2004), Engineering flows In small devices: Microfluidics Toward A Lab-On-AChip. Annual Review of Fluid Mechanics 36: 381-411.

Tarn, MD, Pamme N (2014), Microfluidics, in Reference Module in Chemistry, Molecular Sciences and Chemical Engineering Elsevier.

Tuan NA, Mizunuma H (2013), High-shear drag reduction of surfactant solutions. Journal of NonNewtonian Fluid Mechanics 198: 71-77.
Xie H, Lee H, Youn W, Choi M (2003), Nanofluids containing multi walled carbon nanotubes and their enhanced thermal conductivities. Journal of Applied Physics 94: 4967-4972.

Yang Y, Zhang Z, Grulke EA, Anderson WB, Wu G (2005), Heat transfer properties of nanoparticle-in-fluid dispersions (nanofluids) in laminar flow. International Journal of Heat Mass Transfer 48(6): 1107-1116.

Yu B, Kawaguchi Y (2006), Parametric study of surfactant-induced drag-reduction by DNS. International Journal of Heat and Fluid Flow 27(5): 887-894.

Zhao JF, Luo ZY, Ni MJ, Cen KF (2009), Dependence of nanofluid viscosity on particle size and $\mathrm{pH}$ value. Chinese Physics Letters 26: 066202. 